\title{
Getting Started with Data Management \& DMPTool at WHOI
}

Audrey Mickle

MBLWHOI Library

January 26th, 2017

\section{Overview}

1. Why is data management important?

2. What is a data management plan?

3. The DMPTool

\section{Why is Data Management Important?}

Data sharing allows for reproducibility,

1. Why is data management important?

2. What is a data management plan?

3. The DMPTool

\section{Overview}




\section{Data Management \& Sharing Mandates}

- Journals - PLOS, Nature, JDAP partners

- Funders - NSF, NIH...

- Office of Science \& Technology Policy mandate, February 2013

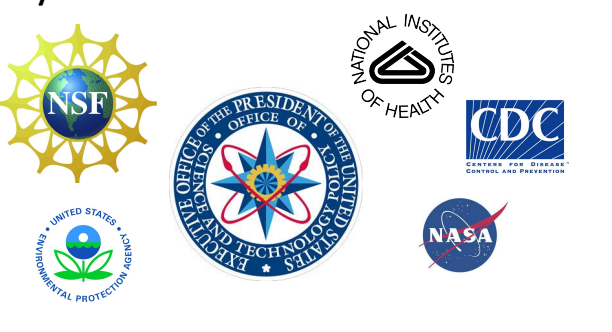

What is a data management plan?

A document that describes what you will do with your data during your research and after you complete your project

\section{Overview}

1. Why is data management important?

2. What is a data management plan?

3. The DMPTool

\section{Why prepare a DMP?}

- Saves time

- Increases research efficiency

- Satisfies funder requirements

- Makes reproducibility \& sharing easier 


\section{A DMP is a Living Document}

- Keep your plan current

- Incorporate changes

- Use as a guide for daily activities

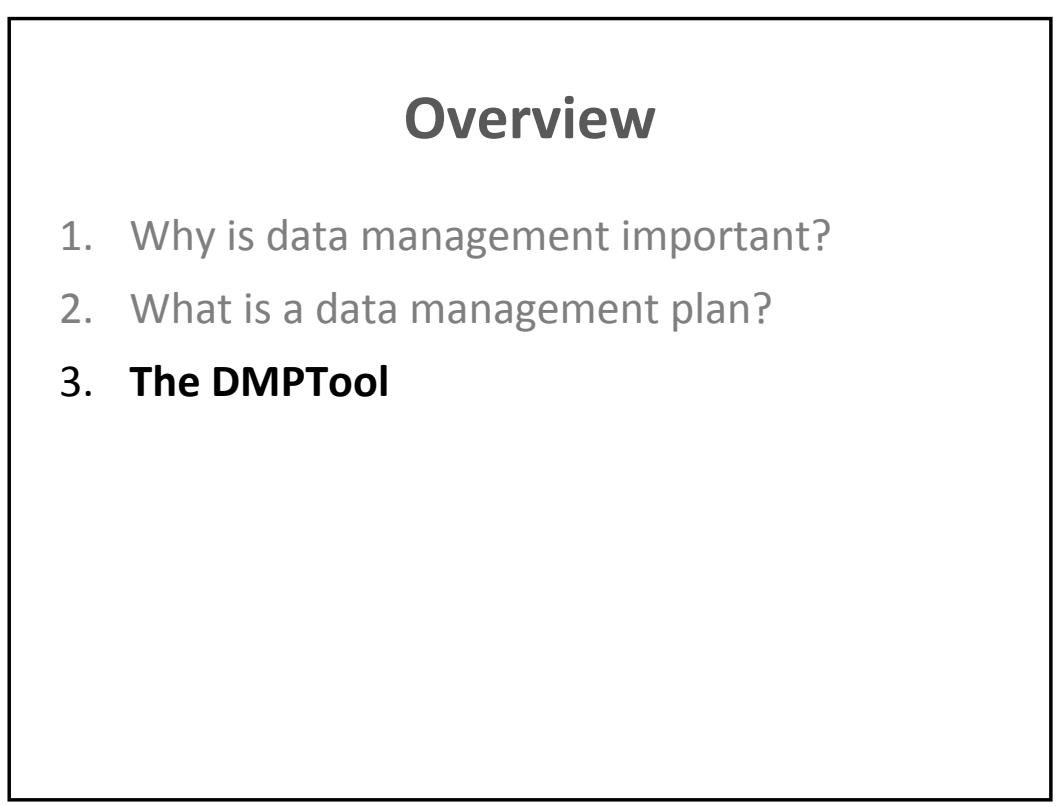

\section{Where to Start?}

\section{Small \& Simple}

- Document what you know now

- Share the plan with your team

- Avoid procrastination and immobilization

\section{DMPTool.org} goo.gl/SLi2jP 

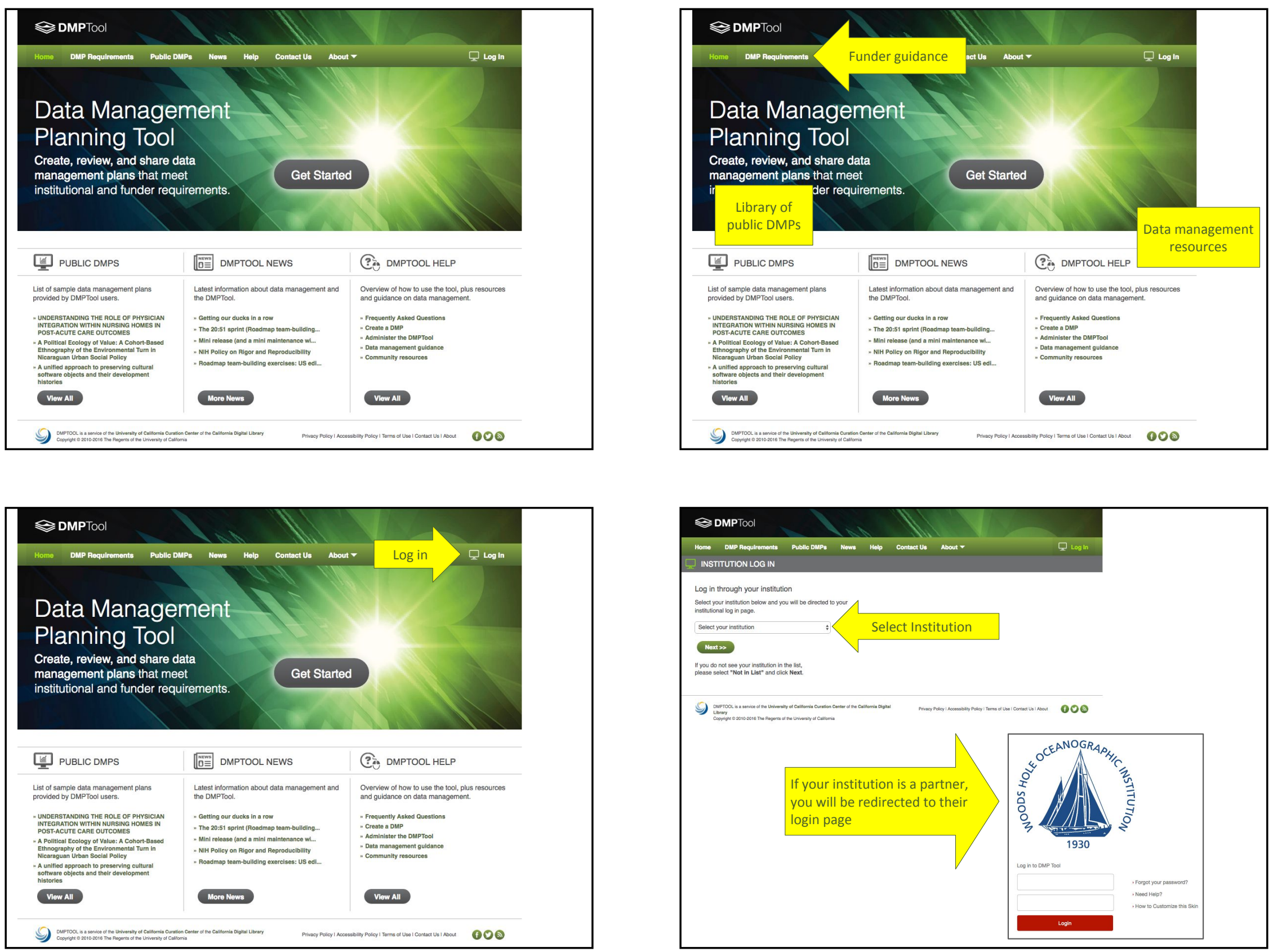

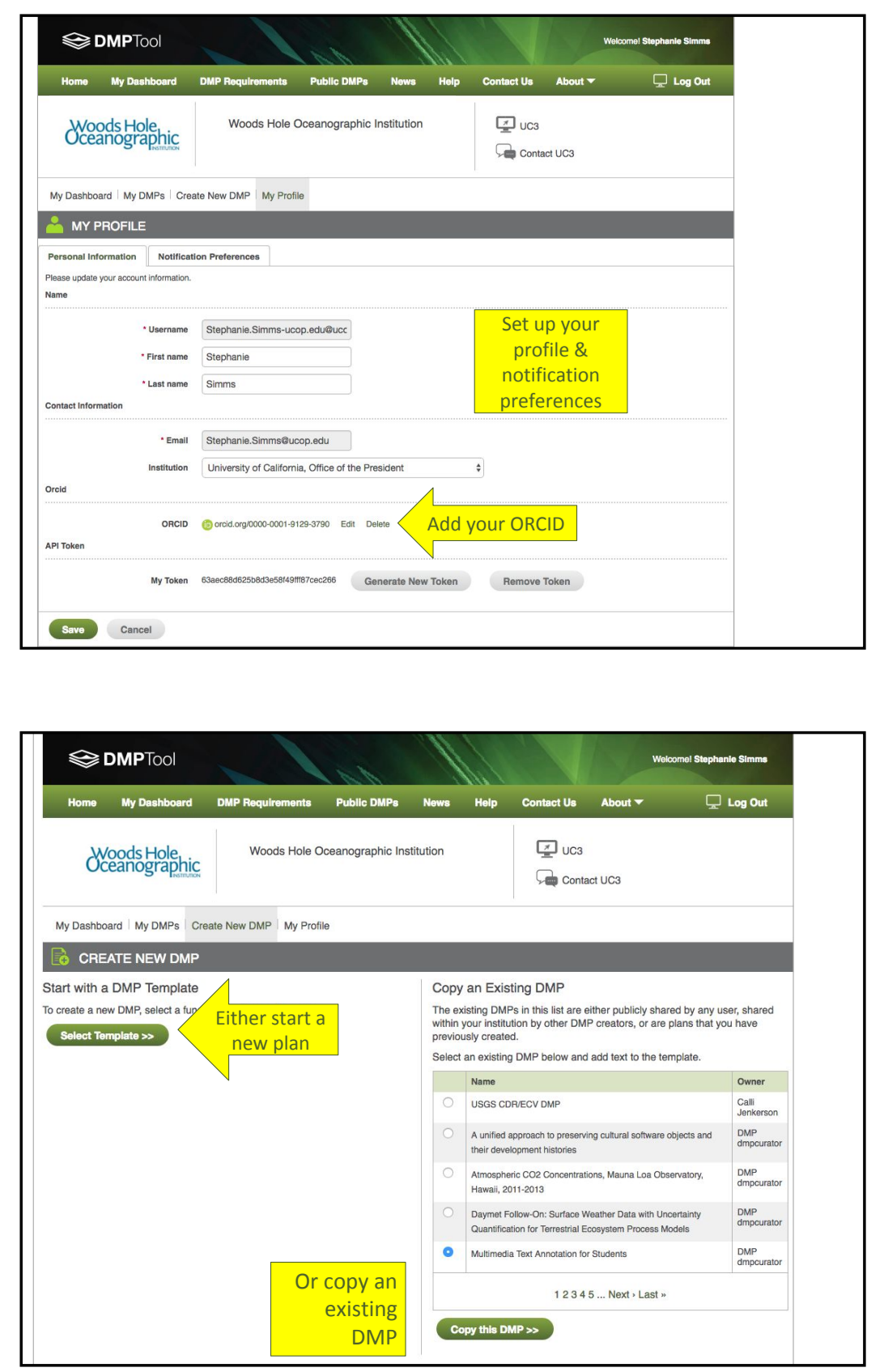
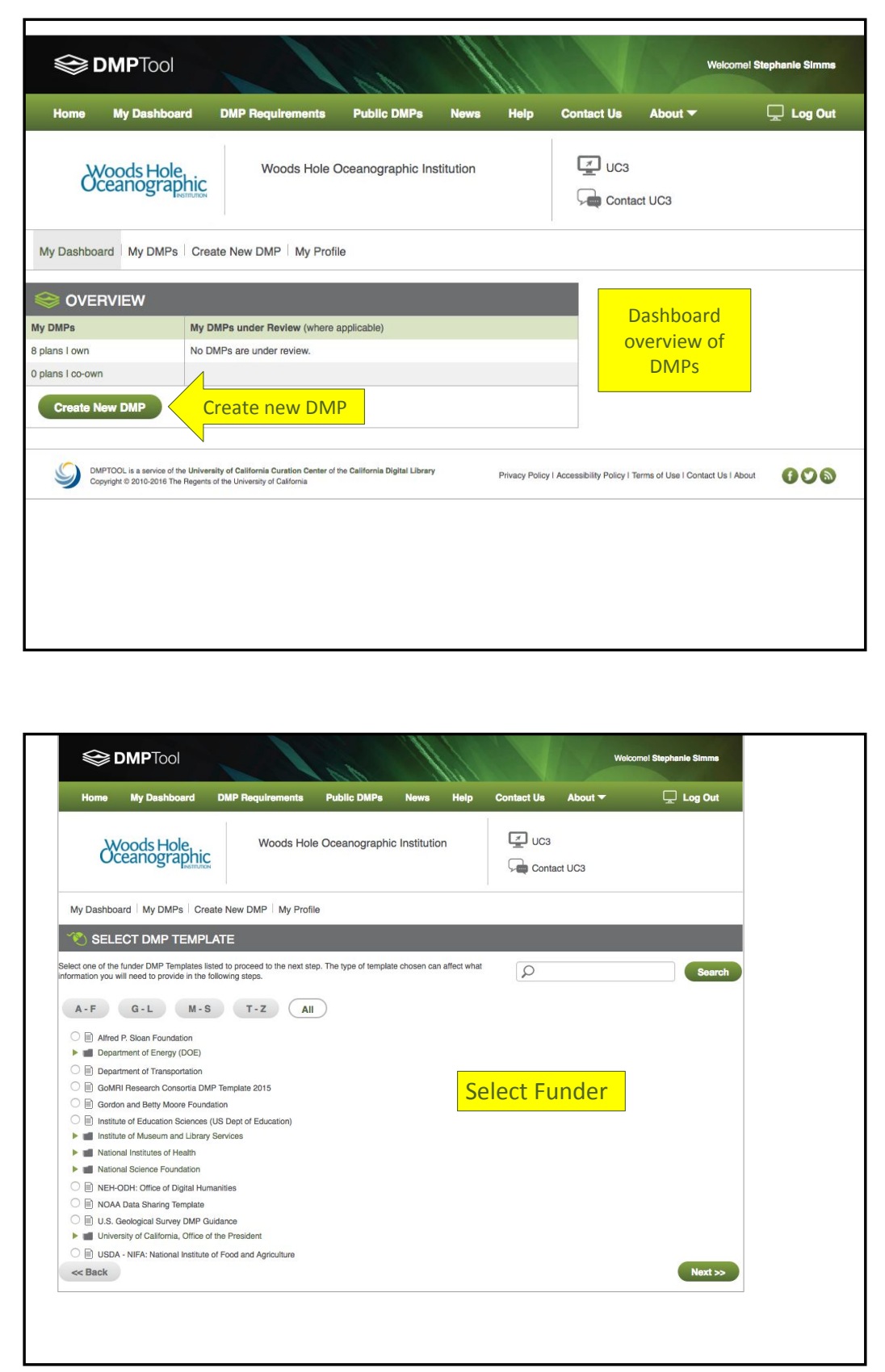

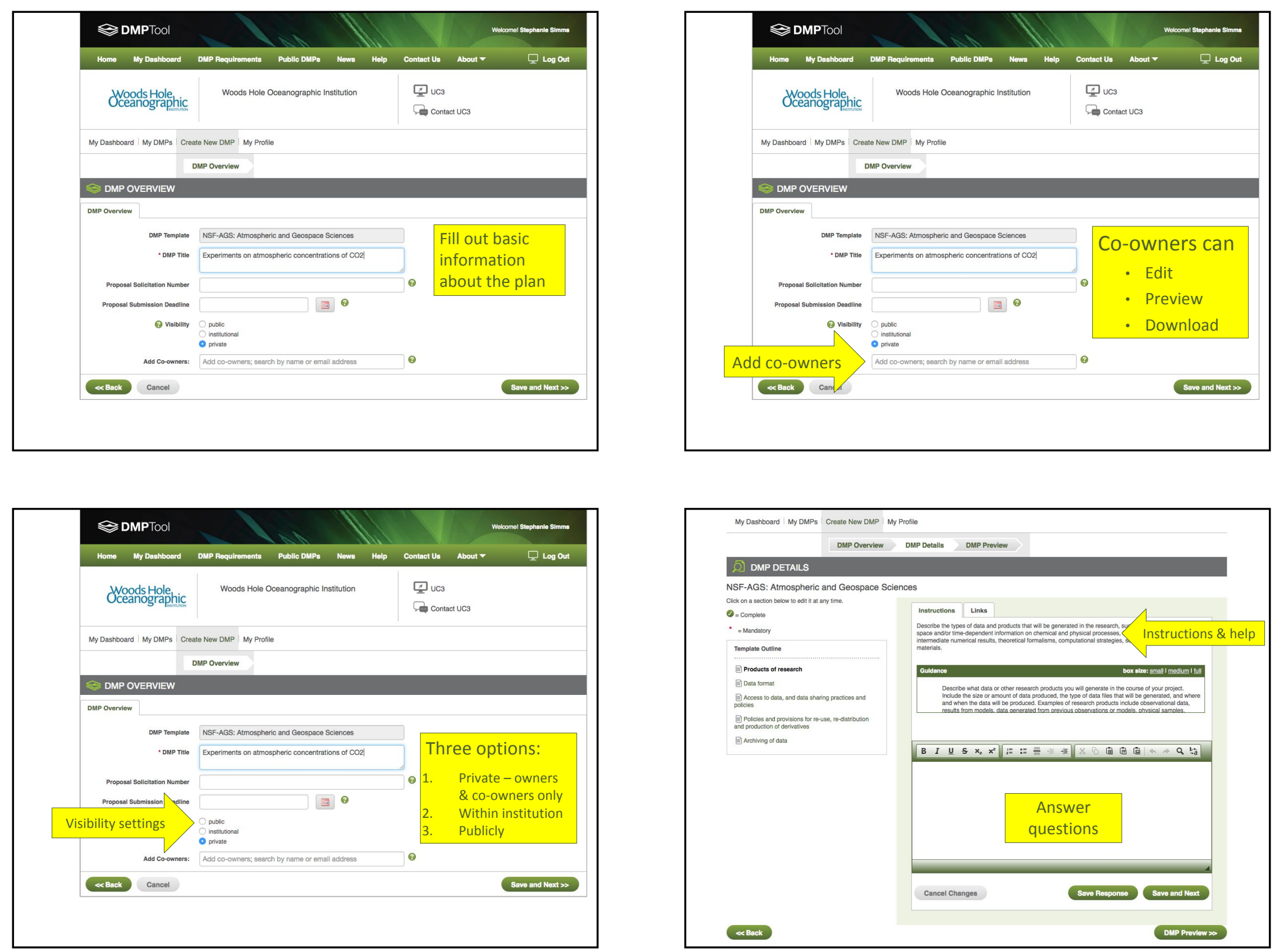


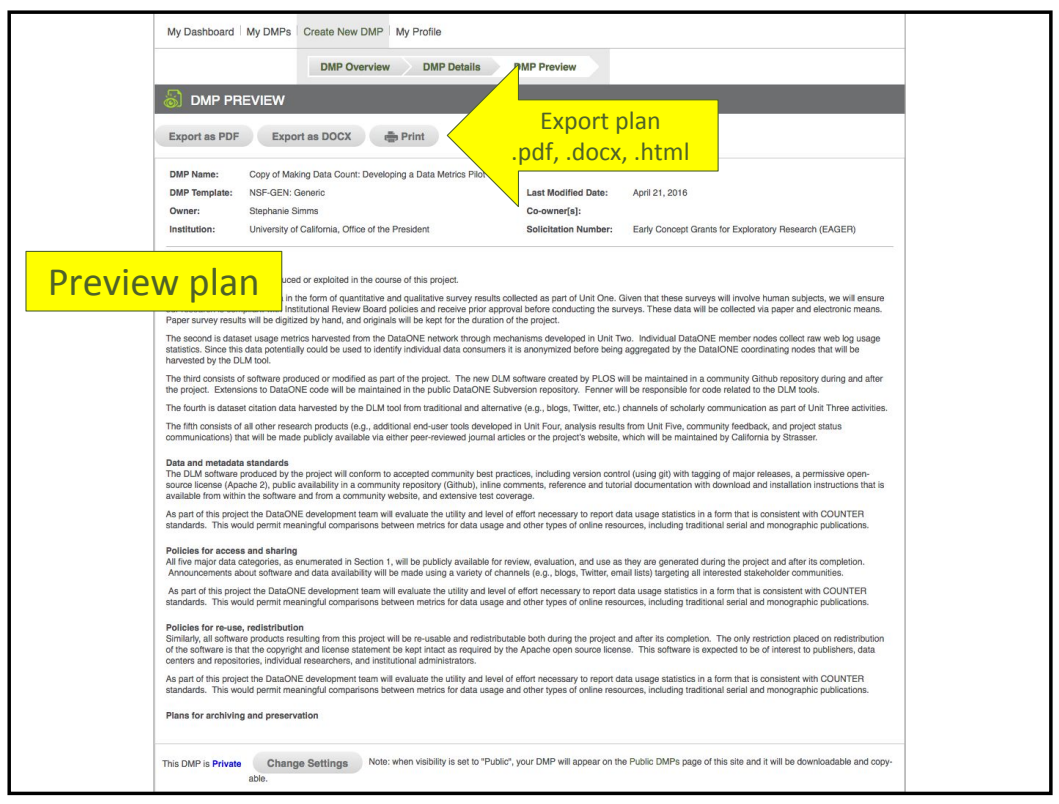

\section{What else?}

- Collaborative tool for co-PIs at different institutions or within a lab

- Keep DMPs from successful proposals for reference

- Customize content and custom templates

- Approval/review process with commenting system
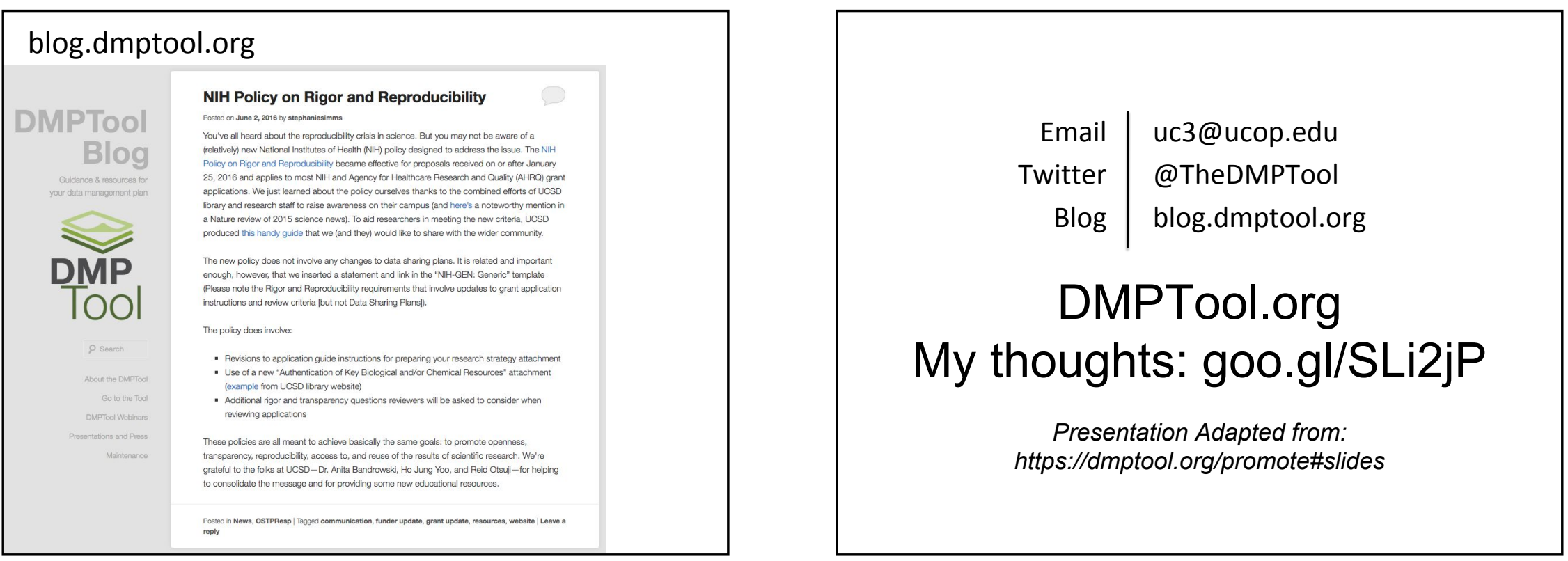